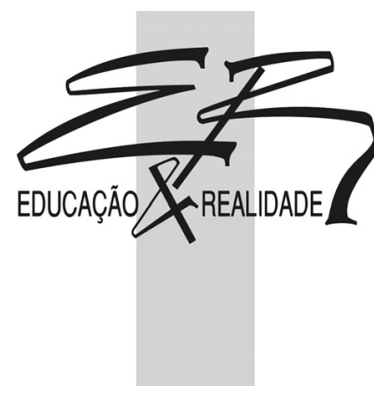

\title{
Memoria e Imagen
}

Leonor Arfuch

RESUMEN - Memoria e Imagen. Imagen y narración se unen de modo indisociable en todo intento - y por ende, en toda política - de transmisión de la memoria. Tanto por la dimensión icónica de la palabra, que hace del relato una pantalla proyectiva de nuestra imaginación - imaginación no menos verdadera que la que atestiguan las imágenes- como por el carácter narrativo de la imagen, aunque ésta requiera a menudo de la vecindad de la palabra. En ambos registros la idea de transmisión - que tiene en el campo educativo una valencia singular - evoca una intencionalidad, una tensión hacia el otro, el destinatario, que pone en juego el movimiento dialógico del discurso - en su más amplia definición - y en este sentido responde en la doble acepción ética de dar respuesta y de responsabilidad. Nos proponemos entonces plantear algunas reflexiones teóricas en torno de la memoria y su relación con la imagen a partir de dos escenas, una literaria (Sebald), la otra de las artes visuales (Christian Boltanski), cuya complementariedad resulta de una curiosa - y no obligada - sintonía. Escenas de una memoria traumática que, a la manera de ciertas iluminaciones benjaminianas, dejan ver un insondable fondo de tragedia.

Palabras-clave: Arte. Memoria. Transmisión. Imagen. Narrativa.

ABSTRACT - Memory and Image. Image and narration are intrinsically related when the transmission of memory is at stake. This is so, not only because of the iconic dimension of the words, that make any story a projective screen of our imagination, but also due to the narrative character of images, although these very often require the proximity of the word. In both cases the idea of transmission, which has a special meaning in the domain of education, has to do with some intentionality, an orientation towards the other, the addressee, in a dialogical interaction where response and responsibility come together in an ethical plane. Our aim here is to pose some theoretical reflections regarding the relation between image and memory by comparing two scenes, one taken from literature (Sebald), and the other from the visual arts (Christian Boltanski), scenes of a traumatic memory, marked by tragedy.

Keywords: Art. Memory. Transmission. Image. Narrative.

Educ. Real., Porto Alegre, v. 37, n. 2, p. 399-408, maio/ago. 2012.

Disponivel em: <http://www.ufrgs.br/edu_realidade> 
Quisiera comenzar con una imagen que no es una imagen, o mejor, que es una imagen literaria, tramada en la profundidad de la palabra, su sin fondo, su poética. Es un fragmento de Austerlitz, la novela del escritor y académico alemán W. G. Sebald, publicada en español en 2002, que tuvo un fuerte impacto en la crítica. La novela es un largo relato donde el narrador, que ha encontrado a un raro personaje, un tal Jacques Austerlitz, en la sala de espera de la estación de trenes de Amberes, nos cuenta sin respiro - quiero decir, sin punto y aparte -, la conversación que ha ido manteniendo con él durante décadas, en distintos encuentros, la mayor parte casuales, en otras estaciones y ciudades, una conversación fascinadora y casi monológica, en la cual Austerlitz, un ser solitario y melancólico, inseparable de su mochila, va relatando - y así sacando a luz - retazos de su vida, una vida atravesada por un misterio que se resiste a su búsqueda, una búsqueda identitaria que lo lleva sin descanso de un lugar a otro - como el sin respiro de la narración. Criado desde muy niño por un predicador galés y su esposa, en un remoto pueblo de montaña, su origen quedó como un secreto llevado a la tumba por esos padres adoptivos, distantes, que sólo dejaron tras de sí un indicio altamente perturbador: que el nombre que lleva no es su verdadero nombre.

En esa búsqueda acuciante y ya desesperanzada, en la mitad de la novela Austerlitz - nos cuenta el narrador - descubre finalmente la clave que lo llevará a descifrar ese misterio. En su infatigable recorrido por distintas estaciones ferroviarias y ciudades de Europa, ha sentido siempre una extraña atracción, plena de confusas sensaciones, por la de Liverpool Street, en Londres, a la que siempre vuelve. Un día, siguiendo a alguien que va hacia un sector desafectado, que ha quedado como resabio de otras estructuras destinado a desaparecer, descubre una vieja sala de espera de señoras, un antiguo Ladies Waiting Room. Entra y se encuentra anonadado por un desencadenamiento súbito de imágenes y recuerdos:

Realmente tenía la sensación, dijo Austerlitz, de que la sala de espera, en cuyo centro estaba yo como deslumbrado, contenía todas las horas de mi pasado, todos mis temores y deseos reprimidos y extinguidos alguna vez, como si el dibujo de rombos negros y blancos de las losas de piedra que tenía a mis pies fuera el tablero para la partida final de mi vida, como si se extendiera por toda la planicie del tiempo. Quizá por eso viera también en la semipenumbra de la sala dos personas de mediana edad vestidas al estilo de los años treinta (los describe...). Y no sólo vi al pastor y su mujer, dijo Austerlitz, sino que vi también al chico que habían venido a buscar. Estaba sentado solo, en un banco apartado. Las piernas, enfundadas en medias blancas hasta la rodilla, no le llegaban al suelo aún y, de no haber sido por la mochila que llevaba abrazada en su regazo, creo, dijo Austerlitz, que no lo habría reconocido. Así, sin embargo, lo reconocí por la mochila" (Sebald, 2002, p. 139). 
Comprendió entonces, hasta donde la ráfaga de la memoria le permitió recordar, que debió ser a esa sala de la estación donde él había llegado, más de medio siglo antes, uno de los tantos niños judíos - esto se le revela tiempo después - que sus padres enviaron fuera del área que iba siendo conquistada por el nazismo con la esperanza de que se salvaran, como refugiados, de la tragedia inminente ${ }^{1}$.

Vuelvo al texto:

Recuerdo sólo que, al ver al chico sentado en el banco, tuve conciencia, por su estupor apático, de la destrucción que el estar solo había producido en mí en el curso de tantos años, y me invadió un terrible cansancio, al pensar que nunca había estado realmente vivo, o que acababa de nacer ahora, en cierto modo en vísperas de mi muerte (Sebald, 2002, p. 139).

Ese "ver" avanza luego, en las páginas siguientes, entre la bruma de las pesadillas y una seria perturbación mental ante tal revelación, que le llevó su tiempo superar:

Me veía solo aguardando, en un muelle, en una doble fila de niños que en su mayoría llevaban mochilas o carteras. Volvía a ver [...] la proa del buque más alta que una casa [...], las gaviotas que, chillando furiosamente, volaban sobre nuestras cabezas... (Sebald, 2002, p. 144).

Una vez descubierto el origen, el deambular de Austerlitz - y el nombre no es aleatorio -, lo llevará, en un impulso irrefrenable, a Praga, donde reencuentra su vieja casa familiar y en ella, a la mujer que lo cuidaba de niño; luego al campo de concentración de Terezin, donde murió su madre y más tarde a París, tras las huellas perdidas de su padre.

¿Porqué Empezar Así, con esta larga introducción?

Primero: este fue el recuerdo que surgió inmediatamente al pensar la relación entre arte, memoria e imagen y entonces, las posibles políticas de transmisión de la memoria en el campo de la educación. Una imagen venida de otra parte que del asedio visual cotidiano - y su violencia - o de los interrogantes que nos suscita la memoria pública o la reflexión teórica. Sin embargo, y como suele suceder con la literatura, esa desgarradora imagen del niño de cuatro años y medio - lo sabremos después -, cuyas piernas no alcanzan el piso, que aparece sin escándalo en una leve flexión de la escritura, contiene no sólo la clave del relato y el descubrimiento de la identidad - una imagen que despierta la memoria, una memoria que despierta la imagen - sino también conceptos claves para todo pensamiento crítico: justamente, la relación intrínseca entre memoria e imagen, la carga afectiva y el impacto corporal que esto supone, su cualidad de acontecimiento, en tanto transformación del estado de las cosas y puesta en juego de la temporalidad, la paradójica tensión entre presencia y ausencia, lo irreductible de la experiencia personal que sin embargo nunca deja de ser colectiva. Vemos allí - como vio Austerlitz insistentemente - dibujarse 
en el fondo de la palabra, en la imagen del barco y del puerto, el sonido y la furia - siguiendo con las marcas literarias - de toda una época. Un ver que en Sebald se complementa siempre con la imagen, extrañas fotografías en blanco y negro que acompañan, sintomáticamente, sus textos.

Pero ¿qué es eso de ver sobre el fondo de la palabra? No otra cosa que su dimensión icónica, esa prodigiosa capacidad del lenguaje, del signo, de aunar una imagen acústica, como la definiera Saussure, con un concepto, que es, potencialmente, también una imagen. Primer señalamiento para no separar estos dos órdenes, lo verbal, lo visual, que consideramos intrínsecamente ligados, aunque no sean, obviamente, lo mismo.

Sobre la relación deslumbradora entre memoria e imagen, su potencialidad de iluminar zonas dormidas, agazapadas, negadas, reprimidas, y hasta sobre esa iconicidad performativa del lenguaje, si se me permite esta expresión, en tanto capacidad casi pictórica de creación y de imaginación, los antiguos griegos reflexionaron largamente. El filósofo Paul Ricoeur retoma sus pasos en su penúltimo gran libro, La memoria, la historia, el olvido (2004), focalizando justamente en el pasaje entre memoria e historia, esencial a toda transmisión. Para Aristóteles, por ejemplo, el recuerdo es imagen y trae consigo, desde la propia etimología, la fantasía y la imaginación; para Platón, el recuerdo es una impronta, a la manera de una huella en la cera - más aún, una afección en el alma - que también se traduce, como huella gráfica, en la escritura.

Ahora bien, ¿Qué es lo que la memoria intenta sustraer al olvido? ¿Y qué es lo que se pretende trasmitir, dejar como huella perdurable en la memoria colectiva? Los hechos del pasado, podría decirse, sorteando la aporía aristotélica de la memoria - el empeño de hacer presente lo que está ausente -, y, en el caso del trauma, con toda su carga de violencia, sufrimiento, aberración y miedo, de modo tal que resulten irrepetibles: he aquí su función ejemplar. Sin embargo, no es tan sencillo responder al qué de la memoria. Se juega en ello, volviendo a Aristóteles, una dimensión objetual - algo que se recuerda; una dimensión física, cortical - una huella en el cerebro -, y, quizá lo más importante, una huella afectiva, que, como vimos en el relato del comienzo, queda como su impronta originaria. Así, al recordar se recuerda una imagen, una especie de pintura dice el filósofo, - con toda la problematicidad de lo icónico: el dilema de la representación, su relación intrínseca con la imaginación y por ende, su debilidad veridictiva (la supuesta verdad de lo que se recuerda) - y la afección que conlleva esa imagen. ¿Qué es entonces lo que trae con más fuerza el recuerdo, la imagen de la cosa ausente o la afección presente? ¿Los hechos o su impronta en la experiencia - individual, colectiva - pasada y actual? Y todavía ¿cómo llega esa imagen al recuerdo, de modo espontáneo o por el trabajo activo, esforzado, de la anamnesis, la rememoración? ${ }^{2}$

Hay, en el relato de Austerlitz, una búsqueda activa del pasado a través de sus indicios y una revelación - ¿rememoración? - que se anticipa al recuerdo mismo de la pérdida, a ese olvido rotundo de la escena traumática que resta como huella inconciente, clásico mecanismo de supervivencia. Pero hay también 
una inquietud, una presunción de aquello que insiste como falta, una marca que impulsa el trabajo del descubrimiento, que lleva, como en los casos de los nietos ilegítimamente apropiados durante la última dictadura militar en la Argentina - con los cuales, pese a la distancia respectiva del acontecimiento y de la historia, hay una cruel similitud - a querer saber más, a enfrentar el miedo a saber, correlato obligado de la angustia del no saber.

Pero como en el caso de Austerlitz, la pintura, para tomar la expresión aristotélica, es decir, la imagen que retorna a la memoria con toda su violencia - la violencia de un alumbramiento - al tiempo que se muestra en sí misma hace referencia a otra cosa: la ausencia que trae indefectiblemente la presencia. La ausencia que conlleva toda aparición - y todo trabajo - de la memoria.

Es por eso quizá que toda imagen, como Jean-Luc Nancy (2003) lo percibiera, tiene un fondo que se nos escapa, no sólo por la ausencia de lo que no está - el fuera de campo que quedará como un enigma, o lo que siempre le falta a aquello que aparece - sino también por esa sombra perturbadora que la temporalidad arroja sobre ella recordándonos la mortalidad: el retrato, la fotografía, la pintura, la impresión grabada en la retina, dan cuenta de ello. Por eso quizá en el fragmento que citamos la irrupción de la memoria trae consigo, de modo fulgurante, la cercanía de la muerte.

Temporalidad de la imagen como pérdida, sutil deslizamiento del tiempo - y allí el fuerte impacto afectivo de la fotografía - y también imágenes del tiempo, como en el trabajo sobre la variación de la luz en la larga tradición de la pintura, la fotografía y el cine. Y aquí habría tal vez un matiz que pudiera agregarse a la teoría de la narrativa de Ricoeur, a su afirmación de que la temporalidad - a diferencia del tiempo en singular - sólo es aprehensible en la narración: también la imagen da cuenta de la temporalidad y entonces es asimismo narrativa.

Imagen y narración se unen así, de modo indisociable, en todo intento - y por ende, en toda política - de transmisión de la memoria. Tanto por la dimensión icónica de la palabra, que hace de todo relato una pantalla proyectiva de nuestra imaginación - imaginación no menos verdadera que la que atestiguan las imágenes - como por el carácter narrativo de la imagen, aunque ésta requiera a menudo de la vecindad de la palabra. En ambos registros la idea de transmisión - que tiene en el campo educativo una valencia singular - evoca una intencionalidad, una tensión hacia el otro, el destinatario, que pone en juego el movimiento dialógico del discurso - en su más amplia definición - y en este sentido responde en la doble acepción de respuesta y de responsabilidad ${ }^{3}$.

Si ese responder es, por definición, ético - acorde a un régimen de verdad, al sistema de valoración que rige cada género discursivo - en el caso de la transmisión de la memoria se transforma en un imperativo, en un deber en función de la justicia, sobre todo respecto de crímenes y acontecimientos traumáticos que dejan memorias imposibles de acallar, cuya temporalidad siempre es el presente. Justicia como ideal de verdad, más allá del poder judicial - aunque pueda convocarlo -, como deuda hacia los predecesores o las víctimas, como 
orientación hacia un futuro que se vislumbra como potencialmente superador.

Ahora bien, dicho esto aparece de inmediato toda la complejidad del tema: ¿qué es lo que se transmite, quién lo hace, de qué manera y para qué? ¿Es posible la transmisión de la memoria si, como afirmaba Maurice Halbwachs (1992), quien por primera vez postulara la expresión memoria colectiva - pocos años antes de morir en el campo de exterminio de Buchenwald -, sólo los individuos recuerdan, si cada uno lleva en sí su propia marca como una experiencia intransferible? ¿Es posible, además, hablar de la memoria en singular, cuando, aun en el esfuerzo de la abstracción, en esa especie de universal que es la memoria colectiva la pluralidad excede todo límite hipotético de consenso no sólo como diferencia sino siempre como conflicto?

Sin embargo, y en tanto uno nunca recuerda solo, como también anotaba Halbwachs, sino en el contexto de su medio social, esa transmisión es la clave y el don que guía el devenir de las generaciones, el principio de reconocimiento y pertenencia, la obligación de la Historia como disciplina y del Estado como garante de la institucionalidad. Múltiples espacios para el despliegue de la memoria, de lo gubernamental a lo familiar, de lo público a lo privado, de lo grupal a aquello que, aun con reparos, puede reconocerse como colectivo. Lo que es también decir, múltiples narrativas en pugna, que confrontan no sólo contenidos sino también concepciones en torno de la representación, modalidades enunciativas, éticas y estéticas, en definitiva, una forma del relato que supone, inequívocamente, su puesta en sentido.

En esta construcción nada es irrelevante: importa tanto una política de Estado en torno del ideal de justicia - como las que hacen posible juzgar a los culpables de crímenes - como la instauración pública de lugares de memoria museos, monumentos, memoriales - o las políticas educativas que incorporan el pasado reciente como objeto de estudio y análisis. Dicho esto, de nuevo se abre el abanico de los interrogantes, en cuanto a las formas, las concepciones, los estilos, el riesgo de la cristalización y la estetización. Para dar sólo un ejemplo: no basta el monumento por sí mismo, como un hito en el camino que al poco tiempo se pierde en el paisaje, es necesario pensar otros modos de la relación, activos, perceptivos, inquietantes, a la manera en que la estética reactiva del anti-monumento opera, marcando más el vacío y la ausencia, la fisura que el trauma deja siempre abierta en una sociedad, que la plenitud compensatoria de una forma acabada y tranquilizadora ${ }^{4}$.

Pero también son necesarias las memorias mínimas, singulares, cotidianas, ésas que despiertan las preguntas entre padres e hijos o maestros y alumnos, que abren el debate familiar o escolar, la curiosidad y la inquietud ante lo que no fue vivido en la propia experiencia. El debate y la inquietud, o la inquietud del debate es quizá el mejor modo de construcción - y transmisión - de la memoria, que por cierto nunca logra eclipsar el olvido.

Entre el registro de la memoria pública, institucional, gubernamental, mediática -y este adjetivo pesa por sí mismo, como bien sabemos -, donde el testimonio y el documento gestionan prioritariamente el tránsito entre memoria 
e historia, y el de la conversación cotidiana, que también tiende a acuñar sentidos y prácticas - ese sentido práctico que según Bourdieu (1991) orienta la acción de los sujetos - hay otro espacio de transmisión, en mi opinión privilegiado: el del arte, en todas sus manifestaciones.

La literatura, por cierto, que surgió como un principio obligado de este diálogo. Desprovista del rigor que se espera del testimonio - el ajuste a una estricta verdad de los hechos, a la vez necesaria e imposible, la aterradora acumulación de los detalles, que a menudo roza el umbral del pudor - y sin embargo capaz de alcanzar toda la crudeza de una experiencia propia y entonces, quizá más cerca de lo colectivo. Austerlitz es, por caso, un admirable ejercicio de transmisión de la memoria, que ejemplifica a su vez la escena emblemática de esa transmisión: el relato que alguien hace de su vida en tanto búsqueda de una memoria perdida, configurándola performativamente como tal, en una unidad inteligible, ante un otro, el tú del narrador. Relato que a su vez el narrador nos transmite instituyéndonos en el tú del presente de la enunciación. Doble distancia del hecho traumático, que permite atemperar tanto la violencia del acontecimiento como la del recuerdo. Abordaje oblicuo, referido, indirecto, tal como el propio Sebald entendía que podía tratarse en la escritura el tema de la solución final. Doble temporalidad de la memoria, a la vez presente y pasado, quizá otra de sus paradojas.

Las artes visuales también se enfrentan al desafío de la distancia y a los dilemas de la representación - así como a la mística de lo irrepresentable -, a la tentación de la literalidad o a la deriva de la metáfora. Violencia del arte de este tiempo - o de todos los tiempos -, que a veces parece competir con la violencia de la imagen que nos asedia en la vida cotidiana, del hecho en sí y de su re/ producción al infinito en gráficas y pantallas. Violencia de la imagen e imagen violenta, entre la mostración y la monstruación, como gusta distinguir Jean-Luc Nancy, aunque la violencia del arte - a diferencia de la violencia a secas, que se agota en sí misma - se distingue por su sin fondo, es decir, allí donde toca lo real, donde se abre a la multiplicidad de la percepción y la interpretación 5 .

Si comencé por imágenes de la literatura quisiera terminar, para hacerles también justicia, con ciertas imágenes del arte que interpelan fuertemente la memoria y cuya sintonía con el fragmento del comienzo se me reveló súbitamente - pero quizá no del todo azarosamente - en una visita al Museo de Arte Moderno de París, poco tiempo después de la lectura de Austerlitz. Se trata de la Reserva del Museo de los Niños, del artista francés Christian Boltanski, una instalación de 1989, donada al Museo, que ocupa dos salas contiguas.

Para este autor, nacido, igual que Sebald, en 1944, la memoria traumática del nazismo y de la segunda guerra también es una fuerte inspiración de su trabajo - él mismo se define como un hijo de la Shoá pese a no haber vivido sus horrores -, que interpela lo colectivo desde una estética narrativa donde prima la alusión y la metáfora por sobre la representación directa. Definido como artista post-conceptual, su obra se caracteriza por la acumulación de elementos comunes, que en sí mismos no tienen ninguna connotación particular, 
pero cuya combinatoria, prioritariamente en instalaciones, resulta altamente perturbadora: ropas - con su relación inmediata con la categoría de persona; cajas de archivo; fotografías esfumadas, a menudo iluminadas por lámparas según cierta tradición judía de homenaje a los muertos; siluetas de madera o cartón sobre las que reposan, como al descuido, vestiduras; galerías de cajas de archivo, en fin, una simbología donde el paso del tiempo, la acechanza de la muerte, lo siniestro cotidiano y la memoria traumática de la Shoá aparecen insistentemente, con diversa acentuación según el caso. Esta objetualidad obsesiva se torna a menudo sobre la infancia: la propia, en sus primeras obras, un libro de artista ficcionalmente llamado Búsqueda y presentación de lo que queda de mi infancia, 1944-1950 y una Colección de objetos que pertenecieron a Christian Boltanski; la de otros niños, cuyo destino trágico es posible aventurar en el tratamiento de las fotografías - ampliadas hasta casi la disolución, fuera de foco, opacadas por sombras, iluminadas por lámparas sobre el rostro que borran alguno de sus rasgos - o en cúmulos de ropa, sin que en ningún caso esos elementos guarden relación con personas y objetos verdaderos. Dicho de otro modo, sin que esas fotografías sean testimoniales, de víctimas conocidas como tales, o las ropas utilizadas provengan de ningún depósito del horror. Al respecto, y como un dato relevante para la comprensión de su obra, el artista explicó alguna vez que en sus instalaciones usaba ropa bien reconocible como contemporánea, lejos de toda pretensión historicista y por cierto, de toda inmediatez con aquello que sólo de forma indirecta y metafórica se quería sugerir.

Al entrar en las salas de la Reserva del Museo de los Niños, el impacto es inmediato: a lo largo de las paredes hay estanterías de metal cubiertas de ropa de niño, cuya aglomeración es sencillamente aterradora. Aquí o allí alguna prenda se desliga del montón y se ofrece a la mirada, en el borde del estante del abismo - como una forma reconocible. En un ángulo - y aquí la conexión, dolorosa e inmediata, como un relámpago, con Austerlitz y la escena evocada al principio - asomaba la parte de abajo de un enterito de bebé, similar a una larga media blanca. Al dejar la sala, un mural de fotografías brumosas, a la manera de una memoria fantasmática, propone quizá un diálogo sin palabras.

$\mathrm{Si}$, como decía Borges, el hecho estético consiste en la inminencia de una revelación que no se produce, la instalación de Boltanski lo cumple en grado sumo, dejándonos al borde de un abismo. Una profundidad ciega donde se mezclan los recuerdos propios con las imágenes que in/forman el acervo colectivo, aquello que quizá pueda llamarse conciencia histórica.

Curiosamente, la instalación completaba - sin revelar nada - el arco temporal de esa historia inconclusa de niños que habían escapado al horrendo destino al que otros habían sucumbido. Y ambas escenas, la literaria y la visual, mostraban, en ausencia de todo detalle, el borde inequívoco de la crueldad.

Confluyen así las dos estaciones de nuestro breve itinerario, donde arte, lenguaje, memoria e imagen han tejido una trama caprichosa, quizás arbitraria, entre órdenes diversos de la poética y de la teoría. Quizás un modo de proponer otros caminos a la reflexión y a la transmisión, donde no solamente prime el 
rigor del método sino también la apertura, ética y estética, a otras dimensiones de la afectividad y la experiencia.

Recebido em março de 2012 e aprovado em junho de 2012.

\section{Notas}

1 Bastante tiempo después de mi lectura de Austerlitz, concretamente el 5 de setiembre de 2009, apareció en el diario Clarín, de Buenos Aires, una noticia que me produjo un enorme impacto, cuyo título era Salvó a chicos del nazismo y ayer pudo volver a abrazarlos. La nota comentaba la extraordinaria empresa de Nicholas Winton, un británico que por razones de trabajo visitó Praga en 1938 y presintió la tragedia que se avecinaba en Europa a partir del avance de Hitler. Comenzó entonces a organizar viajes en tren desde Praga a la estación londinense de Liverpool Street para salvar a los más pequeños de las familias judías. "El británico - rezaba el artículo - logró programar la salida de ocho trenes, en los cuales transportó a Londres a 669 niños, a quienes dio en adopción a familias británicas". La nota celebraba el encuentro de Winton, ya centenario, con 22 de aquellos niños sobrevivientes, hoy ancianos, que llegaron a Londres con cantidad de familiares, después de revivir la travesía en un tren de época, que atravesó durante tres días la ruta europea para llegar a la capital británica a abrazarse con su salvador. Una fotografía del encuentro ilustra la nota. Prueba quizá de que Sebald - un estudioso e investigador infatigable, que vivió en Inglaterra durante más de treinta años, hasta su temprana muerte en un accidente de auto en 2001- conocía bien la historia y elaboró a partir de ella la extraordinaria aventura de su personaje.

2 En el libro citado, Paul Ricoeur indaga minuciosamente la reflexión filosófica en torno de la memoria, desde sus ancestros griegos (fundamentalmente Platón y Aristóteles) a la fenomenología de Husserl y otras corrientes contemporáneas.

3 Remitimos aquí a la concepción bajtiniana que aúna la doble valencia de respuesta y responsabilidad en un plano ético (Bajtín, 1982), concepción que se acerca a la sostenida también por el filósofo rumano Emmanuel Lévinas (1983).

4 La noción de anti o contramonumento (countermonument) fue acunada en el contexto alemán para dar cuenta de una nueva tendencia en cuanto a las políticas - y estéticas - de la memoria, expresada en obras que lejos de reconstituir lo perdido ponían justamente de manifiesto la falta, lo irrecuperable de la pérdida. Así Horst Hoheisel, por ejemplo, diseñó el memorial Piedra Caliente, en el campo de exterminio de Buchenwald, una losa de metal incorruptible con los nombres de todas las naciones que fueron víctimas allí, que señala, sobre el piso, el antiguo lugar donde los sobrevivientes del campo erigieron una pequeña estructura de madera en memoria de sus compañeros, más tarde desaparecida, losa que se mantiene todo el tiempo a temperatura humana $\left(37^{\circ}\right)$. El mismo artista rediseñó una famosa fuente (Aschrott) donada por un rico comerciante judío a la ciudad de Colonia a fines del s. XIX que fuera destruida por los nazis, dejando su trazado original pero en ausencia de la estructura superior, donde el agua corre justamente por debajo, y se la ve y percibe solamente a través de unas rejillas en el piso. Sobre el tema ver Young (2000).

5 He abordado la relación entre arte y memorias traumáticas en Arfuch (2008).

Educ. Real., Porto Alegre, v. 37, n. 2, p. 399-408, maio/ago. 2012. 


\section{Referências}

ARFUCH, Leonor. Crítica Cultural entre Política y Poética. Buenos Aires: Fondo de Cultura Económica, 2008.

BAJTIN, Mijail. Estética de la Creación Verbal. México: Siglo XXI Ediciones, 1982. BOLTANSKI, Christian. Reserva del Museo de los Niños. Paris: Instalación en el Museo de Arte Moderno de París, 1989.

BOURDIEU, Pierre. EI Sentido Práctico. Madrid: Siglo XXI Editores, 1991.

HALBWACHS, Maurice E. On Collective Memory. The University of Chicago Press, 1992.

LÉVINAS, Emmanuel. Le Temps el l'Autre. Paris: Quadrige/Presses Universitaires de France, 1983.

NANCY, Jean-Luc. Au Fond des Images. Paris: Galilée, 2003.

RICOEUR, Paul. La Memoria, la Historia, el Olvido. Buenos Aires: FCE, 2004.

SEBALD, Winfred George. Austerlitz. Barcelona: Anagrama, 2002.

YOUNG, James E. At Memory's Edge. New Haven and London: Yale University Press, 2000.

Leonor Arfuch es doctora en Letras por la Universidad de Buenos Aires, profesora e investigadora de la misma universidad. Trabaja en temas de subjetividad, identidades, memoria y narrativa y en el análisis de géneros discursivos y mediáticos. Es autora de varios libros y ha sido profesora invitada de varias Universidades europeas y latinoamericanas. En 2007 obtuvo la Beca Guggenheim, entre otras distinciones.

E-mail: larfuch@yahoo.com.ar 